\title{
Ingredientes para uma teoria funcionalista da linguagem: bases históricas e desenvolvimentos recentes
}

\author{
André Vinícius Lopes CONEGLIAN (D) \\ Faculdade de Letras - Universidade Federal de Minas Gerais (UFMG)
}

RESUMO

Em sua conferência, Neves vai à funcionalidade da linguagem a partir do conhecimento que se tem construído historicamente sobre a linguagem, examinando, particularmente as ideias desenvolvidas no platonismo, no aristotelismo e no sofismo. A reflexão da autora vai na direção de revelar de que forma o pensamento grego sobre a linguagem fornece os pilares da construção de uma teoria funcionalista da linguagem, chamando a atenção

OPEN ACCESS

EDITADO POR Raquel Freitag (PPGL/UFS)

REVISADO POR Eliabe Procópio

DATAS Recebido: 28/05/2020 Aceito: $29 / 05 / 2020$ Publicado: 29/06/2020

COMO CITAR Coneglian, A. V. L. (2020). Ingredientes para uma teoria funcionalista da linguagem:

bases históricas e desenvolvimentos recentes. Revista da Abralin, v. 19 n. 2, p. 1para as noções de gênero e de estilo, especialmente ligadas à noção de finalidade. Nesta resenha, recuperam-se as bases científicas do funcionalismo discutidas por Neves e apontam-se alguns desdobramentos teóricos de privilegiar a noção de finalidade nas incursões funcionalistas pela linguagem.

\section{ABSTRACT}

In her conference, Neves discusses the aspects of a functional theory of language. She invokes the knowledge that has been historically built about language, and examines ideas developed by Plato, Aristotle and the Sophists. The main point developed by Neves is that the foundations for a functional theory of language was laid by these three distinct philosophical views, drawing special attention to notions such as genre, style and purpose. In this review, I draw on the main points Neves developed in her conference and show some theoretical ramifications of her claims, especially that of putting the notion of purpose at the heart of linguistic investigations. 


\section{REVISTA DA ABRALIN}

PALAVRAS-CHAVE

Funcionalismo. Gramática. Interação.

KEYWORDS

Functionalism. Grammar. Interaction.

\section{Introdução}

Se a história fosse vista como um repositório para algo mais do que anedotas ou cronologias, poderia produzir uma transformação decisiva na imagem da ciência que atualmente nos domina. Kuhn (1962 [2017], p. 59)

A conferência proferida pela Professora Doutora Maria Helena de Moura Neves no ciclo de palestras Abralin Ao Vivo, no dia 20 de maio de 2020, configura uma verdadeira incursão pelo mundo da filosofia grega clássica, em que examina a construção histórica, no Ocidente, do conhecimento sobre a linguagem, assentando as bases reflexivas que permitiram, muitos anos depois, o desenvolvimento de uma teoria linguística funcionalista. Neves tem desenvolvido inúmeros estudos ${ }^{1}$ nessa linha desde o seu doutoramento em Letras clássicas, cujos resultados foram publicados no livro A vertente grega da gramática tradicional: uma visão do pensamento grego sobre a linguagem (NEVES, 1984/2005).

A conferência divide-se em dois momentos: primeiramente, Neves evoca três visões sobre linguagem na filosofia clássica e, com base nelas, mostra o encaminhamento de uma teoria linguística funcionalista, cientificamente estabelecida.

Neves faz uma incursão pelo desenvolvimento histórico do conhecimento sobre a linguagem, passando pelas ideias do platonismo, do aristotelismo e do sofismo. A autora mostra de que modo cada uma dessas visões filosóficas contribuiu para a reflexão sobre a linguagem. O Quadro 1, abaixo, traz os principais pontos discutidos na conferência.

1 A produção da autora (não apenas) nesse tema é vastíssima. Para citar apenas os livros em que se encontram estudos a respeito da emergência da disciplina gramatical entre os gregos e seu impacto no desenvolvimento da ciência linguística, vejam-se Neves (2002, 2010, 2012). 


\section{REVISTA DA ABRALIN}

\begin{tabular}{|l|l|}
\hline Platonismo & $\begin{array}{l}\text { - Movendo-se no campo da lógica, o objetivo de Platão era chegar à verdade das coisas, } \\
\text { como o que Neves (2020) chama de "pura manifestação de sentido humano". } \\
\text { • A busca pela verdade das coisas não pode prescindir da linguagem, porque ela é uma ma- } \\
\text { nifestação humana (imanência), mas a linguagem é um meio imperfeito para chegar à ver- } \\
\text { dade (veja-se especialmente Neves (2005) para essa discussão). } \\
\text { - Entende-se a linguagem como "inerente" ao homem e só por meio dela pode-se chegar à } \\
\text { essência das coisas. }\end{array}$ \\
\hline Aristotelismo & $\begin{array}{l}\text { - Estabelece-se um plano linguístico (o lógos) para a linguagem humana. } \\
\text { - Põe-se foco na linguagem que se representa no mundo político e cultural (o que Neves } \\
\text { chama de "face pessoal" da linguagem); é o homem falando por si e do outro. }\end{array}$ \\
\hline O entendimento do homem como produtor de linguagem implica as noções de estilo e de \\
gênero, desenvolvidos por Aristóteles no território da retórica e da poética. \\
- Entende-se a linguagem como um meio para um fim, o persuadir.
\end{tabular}

QUADRO 1 - Pontos sobre a reflexão da linguagem em três visões filosóficas clássicas. ${ }^{2}$

Aparentemente, essas três visões filosóficas sobre a linguagem não apresentam nenhum ponto de convergência. Entretanto, como argumenta Neves (2020) no segundo momento de sua conferência, o que cada uma delas a seu modo faz é explicitar a criação linguística na vivência da linguagem, ainda que seja para desprezar por completo a linguagem, como é o caso do platonismo. E é justamente na vivência da linguagem, como defende Neves, que está o terreno propício para o desenvolvido de uma teoria funcionalista sobre a linguagem.

A explicitação de uma visão da linguagem em vivência está na citação de Aristóteles, com que Neves abre sua conferência. Diz Aristóteles que "Três são os elementos a distinguir em um discurso: aquele que fala, aquilo sobre que se fala e aquele a quem se fala, e é a este último, o ouvinte, que se relaciona a finalidade" (tradução do grego de Maria Helena de Moura Neves). É extremamente interessante o modo pelo qual Aristóteles equaciona os elementos do discurso, uma vez que ele monta um cenário interacional (obviamente que sem usar o termo 'interacional') muito parecido com o cenário de Dik (1997), na sua proposta funcionalista, em que interlocutores mutuamente influenciam seus estados mentais por meio da produção e interpretação de enunciados. Aí está, pois, a centralidade da finalidade, como um componente básico e da interação, isto é, o que os interlocutores, conjuntamente, buscam alcançar por meio da interação (CLARK, 1996).

2 O Quadro sintetiza a exposição feita por Neves em sua conferência (NEVES, 2020) e traz alguns pontos também desenvolvidos em Neves (2005). 


\section{REVISTA DA ABRALIN}

No desenvolvimento da linguística moderna, especialmente no campo da pragmática e do funcionalismo, a noção de finalidade vem embutida na noção de ato de fala - desenvolvida, lembre-se, também na filosofia (AUSTIN, 1962, SEARLE, 1969). A ideia central por trás da noção de ato de fala, explica Levinson (2017), é a de que os enunciados tanto são portadores de significados (aí entra a semântica) quanto realizam ações (aí entra a pragmática, propriamente).

Em uma direção semelhante, a noção de gênero discursivo também é completamente dependente da noção de finalidade. Já em Aristóteles, como mostra Neves (2020), e na sua proposição dos três gêneros retóricos (o demonstrativo, o judiciário e o deliberativo) a caracterização básica de cada um dos gêneros passa pelo seu enquadre quando a sua finalidade e o público. Na linguística contemporânea, atribui-se a Bakhtin (2003) a noção de gênero como um tipo estável de enunciado. Entretanto, colocando-se de lado essa concepção, também filosófica (e filológica), de gênero discursivo, na visão funcionalista da linguagem, entende-se gênero (discursivo) como um processo social orientado por uma finalidade, ou por um "propósito" nos termos de Martin \& Rose (2008, p. 6).

Nessa visão, o sistema linguístico disponibiliza expedientes por meio dos quais falantes possam construir, discursivamente, suas intenções e finalidades. O domínio construcional (aí entra a sintaxe, propriamente) é responsável por arranjos significativos (semântica) e pela obtenção de efeitos comunicativos (pragmática). Assim amarram-se os três ingredientes para uma proposta funcionalista de estudo científico da linguagem, como indica Neves (2020): o propósito da interação, que se verifica na finalidade dos discursos, as seleções de uso, pertinentes às escolhas sistêmicas que os falantes fazem para a formulação de enunciados, e a não autonomia do sistema da língua, uma vez que os componentes semântico e pragmático governam o que se realiza construcionalmente, por meio da sintaxe.

Ao final, uma última apreciação sobre a conferência. Para além de toda a discussão teórica e do resgate das ideias linguísticas clássicas, talvez a maior lição da conferência de Neves esteja justamente na importância de olhar para o modo como historicamente desenvolveu-se um determinado campo do conhecimento. Nesse ensejo, entra a epígrafe que abre esta resenha. Ora, se como Kuhn (1962 [2017]) argumenta e Neves bem mostrou em sua conferência, a História (com letra maiúscula) deve ser vista mais do que uma anedota ou do que alguma coisa reconhecida apenas misticamente. Tanto a falta de conhecimento quanto a má interpretação da história de uma determinada disciplina podem levar a práticas científicas desastrosas e a revoluções científicas com bases muito frágeis, que, afinal, apenas se pretendem como revoluções. No que diz respeito ao campo da Linguística e da Gramática, Neves, respondendo a uma das perguntas após a conferência, fez questão de mostrar que as noções de GRAMÁTICA NORMATIVA e de GRAMÁTICA TRADICIONAL não são sinônimas, muito MENOS dizem respeito à mesma entidade. Por aí se vê a necessidade de uma base teoricamente sólida, sustentada por pilares da construção histórica do conhecimento sobre a linguagem. E foi exatamente um exame seguro da História das ideias sobre linguagem que Neves proveu em sua conferência. 


\section{REVISTA DA ABRALIN}

REFERÊNCIAS

ARISTOTE. Rhétorique. Texte établi et traduit par M. Dufour et A. Wartelle. Paris: Les Belles Lettres, 1973.

AUSTIN, J. L. How to do things with words. Oxford: The Clarendon Press, 1962.

BAKHTIN, M. Estética da criação verbal. $4^{\mathrm{a}}$ ed. Tradução de Paulo Bezerra. São Paulo: Editora Martins Fontes, 2003.

CLARK, H. H. Using language. Cambridge: Cambridge University Press, 1996.

KUHN, T. A estrutura das revoluções científicas. Tradução de Beatriz V. Boeira e Nelson Boeira. 13ª ed. São Paulo: Editora Perspectiva, 2017 [1962].

LEVINSON, S. Speech acts. In: HUANG, Y. The Oxford handbook of pragmatics. Oxford: Oxford University Press, 2017.

MARTIN, J. R.; ROSE, D. Genre relations: mapping culture. Londres: Equinox, 2008.

NEVES, M. H. M. A gramática: história, teoria e análise, ensino. São Paulo: Ed. UNESP, 2002.

NEVES, M. H. M. A vertente grega da gramática tradicional - uma visão do pensamento grego sobre a linguagem. São Paulo: Ed. UNESP, 2005.

NEVES, M. H. M. Ensino de língua e vivência de linguagem. São Paulo: Contexto, 2010.

UMA visita aos pilares da construção de uma visão funcionalista da linguagem. Conferência apresentada por Maria Helena de Moura Neves [s.l., s.n.], 2020. 1 vídeo (1h 46min 35s). Publicado pelo canal da Associação Brasileira de Linguística. Disponível em: https://www.youtube.com/watch?v=05GhFNpDqfg. Acessado em 8 de junho de 2020 .

SEARLE, J. Speech acts: an essay in the philosophy of language. Cambridge: Cambridge University Press, 1969. 